\title{
The profitability of using mechanical treatments, herbicides and biostimulants in the cultivation of the edible potato cultivar Bartek
}

\author{
Opłacalność stosowania zabiegów mechanicznych, herbicydów \\ i biostymulatorów w uprawie ziemniaka odmiany Bartek
}

\author{
Krystyna Zarzecka*, Marek Gugała, Kornelia Grzywacz
}

\section{Summary}

The aim of the research was to determine economic efficiency of the applied mechanical treatments, herbicides and biostimulants in the cultivation of Bartek, edible potato cultivar. The research was carried out in the period 2012-2014. Five methods of application of herbicides and biostimulants were compared. The first method included the control object without herbicides and four objects with herbicides and biostimulants such as Harrier 295 ZC (linuron + chlomazon), Harrier 295 ZC (linuron + chlomazon) + Kelpak SL, Sencor 70 WG (metribuzin) and Sencor 70 WG (metribuzin) + Asahi SL. Combined use of mechanical and chemical treatments was more profitable than mechanical treatments alone. The best economic effect was recorded for the object where intensive mechanical care consisting of ridging twice and ridging with harrowing once were performed and the combined application of Sencor 70 WG (metribuzin) and Asahi SL.

Key words: economic effect, growth regulators, herbicide products, Solanum tuberosum L.

\section{Streszczenie}

Celem badań było określenie efektywności ekonomicznej stosowania zabiegów mechanicznych, herbicydów i biostymulatorów w uprawie ziemniaka jadalnego odmiany Bartek. Badania przeprowadzono w latach 2012-2014. Porównywano pięć sposobów aplikacji herbicydów i biostymulatorów, takich jak: obiekt kontrolny, bez użycia herbicydów, w kolejnych czterech obiektach aplikowano herbicydy i biostymulatory: Harrier 295 ZC (linuron + chlomazon), Harrier 295 ZC (linuron + chlomazon) + Kelpak SL, Sencor 70 WG (metrybuzyna) oraz Sencor 70 WG (metrybuzyna) + Asahi SL. Stosowane na plantacji zabiegi mechaniczno-chemiczne były bardziej opłacalne, niż pielęgnacja wyłącznie mechaniczna. Z porównywanych obiektów najlepszy efekt ekonomiczny stwierdzono po zastosowaniu intensywnej pielęgnacji mechanicznej obejmującej dwukrotne obredlanie oraz jednokrotne obredlanie z bronowaniem, oraz po łącznym zastosowaniu preparatów Sencor 70 WG (metrybuzyna) i Asahi SL.

Słowa kluczowe: efekt ekonomiczny, regulatory wzrostu, preparaty chwastobójcze, Solanum tuberosum L.

Uniwersytet Przyrodniczo-Humanistyczny w Siedlcach

Katedra Agrotechnologii

Prusa 14, 08-110 Siedlce

*corresponding author: kzarzecka@uph.edu.pl 


\section{Wstęp / Introduction}

Na wzrost i rozwój ziemniaka oddziałuje wiele czynników agrotechnicznych i środowiskowych, od których zależy wielkość i jakość plonu (Krzysztofik i wsp. 2009; Gugała i wsp. 2010). Jest to roślina wrażliwa na zachwaszczenie ze względu na początkowy powolny wzrost oraz uprawę w szerokiej rozstawie rzędów. Stąd istotnym czynnikiem są trafnie dobrane zabiegi redukujące zachwaszczenie. Według Urbanowicza (2015) najskuteczniejszym sposobem ograniczania zachwaszczenia jest zastosowanie herbicydów. Zdaniem Paradiković i wsp. (2011) oraz Trawczyńskiego (2014) czynnikiem wpływającym negatywnie na uprawę roślin są stresy środowiskowe, które obecnie można ograniczać lub redukować, stosując stymulatory wzrostu nazywane biostymulatorami. Biostymulatory są preparatami, które w naturalny i bezpieczny dla środowiska sposób wspomagają procesy życiowe roślin (Wereszczaka i Marczakiewicz 2014; Baranowska i wsp. 2018). Według Mierzejewskiej (1991), aby skutecznie i opłacalnie zapobiegać obniżeniu plonu, a także minimalizować zagrożenia spadku efektywności innych nakładów należy zastosować chemiczną ochronę roślin.

Celem badań było określenie efektywności ekonomicznej stosowanych zabiegów mechanicznych, herbicydów i biostymulatorów w uprawie ziemniaka jadalnego odmiany Bartek.

\section{Materiały i metody / Materials and methods}

Materiał badawczy stanowiły wyniki badań pochodzące $\mathrm{z}$ eksperymentu polowego przeprowadzonego w latach 2012-2014 w Przedsiębiorstwie Wielobranżowym „Soleks”, w miejscowości Wojnów, w województwie mazowieckim. Doświadczenie polowe prowadzono na glebie lekkiej,o pH 5,6-6,35, klasy bonitacyjnej IVb, zaliczanej do kompleksu żytniego bardzo dobrego. Warunki pogodowe w latach badań były zróżnicowane. Według współczynnika hydrotermicznego Sielianinowa rok 2012 był suchy, 2013 umiarkowanie wilgotny, a 2014 dość suchy (Skowera 2014). W doświadczeniu uprawiano średnio wczesną, jadalną odmianę ziemniaka Bartek. Powierzchnia poletka wynosiła $18,75 \mathrm{~m}^{2}(5,55 \mathrm{~m} \times 3,375 \mathrm{~m})$, natomiast do zbioru $15,0 \mathrm{~m}^{2}$ (odrzucono skrajną redlinę). Wariantami badań było pięć sposobów stosowania zabiegów mechanicznych, herbicydów i herbicydów z biostymulatorami:

1. obiekt kontrolny - pielęgnacja mechaniczna, która obejmowała dwukrotne obredlanie oraz jednokrotne obredlanie $\mathrm{z}$ bronowaniem przed wschodami roślin ziemniaka i dwukrotne obredlanie po wschodach rośliny uprawnej,

2. do wschodów wykonano jednokrotne obredlanie oraz zastosowano herbicyd Harrier 295 ZC (linuron + chlo- mazon) w dawce $2,0 \mathrm{dm}^{3} /$ ha po upływie około 7-10 dni od posadzenia bulw,

3. do wschodów wykonano jednokrotne obredlanie oraz zastosowano herbicyd Harrier 295 ZC (linuron + chlomazon) w dawce $2,0 \mathrm{dm}^{3} /$ ha po upływie $7-10 \mathrm{dni}$ oraz dwukrotnie aplikowano bioregulator Kelpak SL w dawkach po 2,0 $\mathrm{dm}^{3} /$ ha, pierwszą dawkę w fazie końcowej wschodów roślin ziemniaka, natomiast drugą dawkę podczas zakrywania międzyrzędzi,

4. do wschodów dwukrotne obredlanie i jednokrotne obredlanie $\mathrm{z}$ bronowaniem, a tuż przed wschodami ziemniaka zastosowano herbicyd Sencor 70 WG (metrybuzyna) w dawce $1,0 \mathrm{~kg} / \mathrm{ha}$,

5. do wschodów dwukrotne obredlanie oraz jednokrotne obredlanie $\mathrm{z}$ bronowaniem, a tuż przed wschodami zastosowano herbicyd Sencor 70 WG (metrybuzyna) w dawce $1,0 \mathrm{~kg} / \mathrm{ha}$ oraz dwukrotnie aplikowano biostymulator Asahi SL w dawkach po $1,0 \mathrm{dm}^{3} /$ ha, pierwszą pod koniec wschodów roślin ziemniaka, a drugą dawkę podczas zakrywania międzyrzędzi.

Każdego roku przedplonem ziemniaka była pszenica ozima. Jesienią przed sadzeniem stosowano nawożenie naturalne w postaci obornika bydlęcego $\mathrm{w}$ dawce $25,0 \mathrm{t} / \mathrm{ha}$ oraz nawożenie mineralne: potasowe $\mathrm{w}$ dawce $124,5 \mathrm{~kg} \mathrm{~K} / \mathrm{ha}$, fosforowe w ilości 44,0 P kg/ha. Wiosną wysiewano nawozy azotowe w dawce $100 \mathrm{~kg} / \mathrm{ha}$, które wymieszano z glebą za pomocą kultywatora.

Bulwy ziemniaka sadzono w trzeciej dekadzie kwietnia i w pierwszej dekadzie maja, w rozstawie rzędów $67,5 \mathrm{~cm}$ i odległości w rzędzie co $37 \mathrm{~cm}$. Każdy obiekt składał się $\mathrm{z}$ pięciu redlin, które oddzielone były pasami ochronnymi. Zbiór ziemniaka przeprowadzono w pierwszej dekadzie września. Po zbiorze dokonano podziału bulw na frakcje: poniżej 35, 35-50, 50-60 i powyżej $60 \mathrm{~mm}$. Za plon handlowy przyjęto bulwy o średnicy powyżej $35 \mathrm{~mm}$ oraz bez wad wewnętrznych i zewnętrznych (Rozporządzenie 2003).

Ekonomiczną ocenę zabiegów ochrony roślin ziemniaka wykonano za pomocą mierników efektywności zabiegów. Pierwszy z nich to nadwyżka produkcji uratowanej $(\mathrm{N})$ obliczona według formuły:

$$
N=P_{u}-K_{Z}
$$

$P_{u}$ - wartość uratowanego plonu (produkcja uratowana), $K_{Z}-$ koszty ochrony.

Drugim, najczęściej stosowanym miernikiem jest wskaźnik pokrycia kosztów $\left(W_{p k}\right)$, który jest ilorazem wartości uratowanego plonu i kosztu zabiegu, wyrażony wzorem:

$$
W_{p k}=\frac{P_{u}}{K_{Z}}
$$

$P_{u}$ - wartość uratowanego plonu,

$K_{Z}-$ koszty ochrony. 
Wskaźnik pokrycia kosztów nazywany jest również wskaźnikiem efektywności. Jeżeli uzyskana wartość wskaźnika jest wyższa od jedności to określa ona, w jakim stopniu plon uratowany pokrył koszty poniesione na ochronę, oznacza to, że zastosowana ochrona na plantacji była opłacalna. Mniejszy wskaźnik efektywności od jedności wskazuje, że koszty ochrony nie zostały zrekompensowane wartością plonu uratowanego. Im wskaźnik pokrycia kosztów jest większy od jedności tym opłacalność zabiegów na plantacji jest korzystniejsza.

Kolejnym miernikiem efektywności zabiegów ochrony jest wskaźnik zwrotu kosztów ochrony, który jest ilorazem nadwyżki produkcji uratowanej i kosztów zabiegów ochrony, przedstawiamy go za pomocą następującej formuły:

$$
P_{w k z}=\frac{N}{K_{Z}} \times 100 \%
$$

$N$ - nadwyżka produkcji uratowanej (zł/ha),

$K_{Z}-$ koszt faktyczny zabiegu (zł/ha).

Efektywność ekonomiczną zastosowanych zabiegów ochrony roślin kalkulowano również za pomocą mierników, które nie uwzględniają wielkości uratowanego plonu. Są nimi orientacyjne wskaźniki opłacalności, określane również równoważnikami kosztów zabiegów $E_{1}$ i $E_{2}$ :

$$
E_{1}=\frac{K_{Z}}{C} \quad \text { i } \quad E_{2}=\frac{K_{Z}}{W_{p}} \times 100 \%=\frac{E_{1} \times 100}{P}
$$

$E_{1}$ - wagowa ilość plonu w dt pokrywająca koszty zabiegu,

$K_{Z}$ - koszty chemicznej ochrony roślin,

$C$ - cena 1 dt ziemniaków,

$E_{2}$ - procentowy wskaźnik opłacalności zabiegu, wyraża procent plonu plantacji chronionej,

$W_{p}$ - wartość plonu ziemniaków (plon $\times$ cena) $($ Mierzejewska 1989, 1991).

Na kształtowanie się powyższych wskaźników ekonomicznej efektywności zabiegów mają wpływ ceny środków produkcji, ceny zbytu ziemiopłodów oraz osiągane plony (Gugała i Zarzecka 2006; Kulig i wsp. 2006; Pytlarz-Kozicka i Golinowska 2006; Golinowska 2009).

\section{Wyniki i dyskusja / Results and discussion}

Na obiektach (2-5), na których zastosowano pielęgnację mechaniczną, a następnie herbicydy lub herbicydy i biostymulatory, zachwaszczenie było mniejsze, a plon handlowy bulw wynosił średnio 346,7 dt/ha i był większy w stosunku do obiektu kontrolnego o $111 \mathrm{dt} / \mathrm{ha}$ (tab. 1). Wyniki dotyczące zachwaszczenia plantacji przedstawiono we wcześniejszej pracy Gugały i wsp. (2018). Krzysztofik i wsp. (2009) oraz Gugała i wsp. (2013) również stwierdzili, że zabiegi mechaniczno-chemiczne korzystnie oddziaływały na udział plonu handlowego w plonie ogólnym. Zarzecka i wsp. (2014) zaobserwowali, że po zastosowaniu herbicydów i ich mieszanin plon uboczny (bulwy małe oraz wadliwe) był mniejszy w odniesieniu do obiektu odchwaszczanego wyłącznie mechanicznie. W prowadzonych badaniach większy plon handlowy otrzymano w wariancie 5., na którym oprócz pielęgnacji mechanicznej zaaplikowano herbicyd Sencor 70 WG (metrybuzyna) oraz biostymulator Asahi SL i wynosił on $389,1 \mathrm{dt} / \mathrm{ha}$, natomiast najmniejszy plon zebrano z obiektu kontrolnego - 341,0 dt/ha.

W prowadzonych badaniach koszty ogółem były zróżnicowane w zależności od sposobu pielęgnacji i kształtowały się na poziomie od 578,2 do 1702,7 zł/ha (tab. 2). Najtańszym sposobem pielęgnacji był obiekt 2., na którym zastosowano herbicyd Harrier 295 ZC (linuron + chlomazon), koszty w tym wariancie wynosiły 578,2 zł/ha. Najbardziej kosztowna była pielęgnacja na obiekcie 5., na którym zastosowano herbicyd Sencor 70 WG (metrybuzyna) i biostymulator Asahi SL, koszty tej pielęgnacji wynosiły 1702,7 zł/ha. Największe koszty pracy ludzkiej odnotowano na obiekcie pierwszym i ostatnim, stanowiły one 195,2 zł/ha.

W tabeli 3. zaprezentowano wskaźniki opłacalności dla poszczególnych obiektów. Wskaźnik pokrycia kosztów $W_{p k}$,

Tabela 1. Plony ziemniaka odmiany Bartek (średnio z lat 2012-2014)

Table 1. Yields of Bartek cultivar (mean for 2012-2014)

\begin{tabular}{l|c|c|c}
\hline \multirow{2}{*}{$\begin{array}{c}\text { Sposoby stosowania herbicydów i biostymulatorów } \\
\text { Methods of application of herbicides and biostimulants }\end{array}$} & \multicolumn{3}{|c}{$\begin{array}{c}\text { Plony bulw - Yields of potato } \\
\text { [dt/ha] }\end{array}$} \\
\cline { 2 - 4 } & $\begin{array}{c}\text { plon ogólny } \\
\text { total yield }\end{array}$ & $\begin{array}{c}\text { plon handlowy } \\
\text { market yield }\end{array}$ & $\begin{array}{c}\text { \% udział plonu handlowego w plonie ogólnym } \\
\text { \% share of the market yield in the total yield }\end{array}$ \\
\hline 1. PM - pielęgnacja mechaniczna - mechanical weeding & 341,0 & 235,7 & 75,8 \\
2. PM* + Harrier 295 ZC & 378,9 & 297,4 & 78,5 \\
3. PM + Harrier 295 ZC + Kelpak SL & 408,8 & 338,9 & 82,9 \\
4. PM + Sencor 70 WG & 427,9 & 361,4 & 84,5 \\
5. PM + Sencor 70 WG + Asahi SL & 447,1 & 389,1 & 87,0 \\
\hline Średnio dla obiektów 2-5 - Mean for object 2-5 & 415,7 & 346,7 & 83,4 \\
\hline
\end{tabular}

*PM - pielęgnacja mechaniczna - mechanical weeding 
Tabela 2. Koszty ochrony ziemniaka odmiany Bartek przed chwastami (średnio z lat 2012-2014) [zł/ha] Table 2. Costs of protection of Bartek cultivar against weeds (mean for 2012-2014) [PLN/ha]

\begin{tabular}{|c|c|c|c|c|c|}
\hline \multirow[t]{2}{*}{ Wyszczególnienie - Specification } & \multicolumn{5}{|c|}{$\begin{array}{l}\text { Sposoby stosowania herbicydów i biostymulatorów } \\
\text { Methods of application of herbicides and biostimulants }\end{array}$} \\
\hline & $1 *^{*}$ & 2. & 3. & 4. & 5. \\
\hline $\begin{array}{l}\text { 1. Koszty pracy ludzkiej razem - Total costs of human labour } \\
\text { a. obredlanie - ridger } \\
\text { b. obredlanie z bronowaniem - ridger with harrow } \\
\text { c. opryskiwanie - spraying }\end{array}$ & $\begin{array}{c}195,2 \\
146,4 \\
48,8 \\
-\end{array}$ & $\begin{array}{c}61,0 \\
36,6 \\
- \\
24,4\end{array}$ & $\begin{array}{c}109,8 \\
36,6 \\
- \\
73,2\end{array}$ & $\begin{array}{l}146,4 \\
73,2 \\
48,8 \\
24,4\end{array}$ & $\begin{array}{l}195,2 \\
73,2 \\
48,8 \\
73,2\end{array}$ \\
\hline $\begin{array}{l}\text { 2. Koszty eksploatacji sprzętu razem - Total costs of machine operation } \\
\text { a. obredlanie - ridger } \\
\text { b. obredlanie z bronowaniem - ridger with harrow } \\
\text { c. opryskiwanie - spraying }\end{array}$ & $\begin{array}{l}790,4 \\
592,8 \\
197,6 \\
-\end{array}$ & $\begin{array}{c}247,0 \\
148,2 \\
- \\
98,8\end{array}$ & $\begin{array}{c}444,6 \\
148,2 \\
- \\
296,4\end{array}$ & $\begin{array}{c}592,8 \\
296,4 \\
197,6 \\
98,8\end{array}$ & $\begin{array}{l}790,4 \\
296,4 \\
197,6 \\
296,4\end{array}$ \\
\hline 3. Koszty herbicydów - Costs of herbicides & - & 166,0 & 166,0 & 190,0 & 190,0 \\
\hline 4. Koszty biostymulatorów - Costs of biostimulators & - & - & 212,0 & - & 220,0 \\
\hline 5. Razem koszty bezpośrednie $(1+2+3+4)$ - Direct costs $(1+2+3+4)$ & 985,6 & 474,0 & 932,4 & 929,2 & 1395,6 \\
\hline $\begin{array}{l}\text { 6. Koszty pośrednie }(10 \% \text { kosztów bezpośrednich } 1+2+3+4) \\
\text { Indirect costs }(10 \% \text { direct costs } 1+2+3+4)\end{array}$ & 98,0 & 47,4 & 93,2 & 92,9 & 139,6 \\
\hline 7. Koszty pozostałe - Other costs & 118,3 & 56,8 & 111,9 & 111,5 & 169,5 \\
\hline 8. Koszty ogółem $(7+8)-$ Total costs $(7+8)$ & 1202,5 & 578,2 & 1137,5 & 1133,6 & 1702,7 \\
\hline
\end{tabular}

*objaśnienia jak w Materiałach i metodach - explanations as in the Materials and methods

Tabela 3. Efekty produkcyjno-ekonomiczne stosowanych herbicydów i biostymulatorów w odmianie Bartek Table 3. Effects of production and economics of used herbicides and biostimulants in Bartek cultivar

\begin{tabular}{|c|c|c|c|c|c|c|c|c|c|}
\hline \multirow{3}{*}{$\begin{array}{l}\text { Sposoby stosowania } \\
\text { herbicydów } \\
\text { i biostymulatorów } \\
\text { Methods } \\
\text { of application } \\
\text { of herbicides } \\
\text { and biostimulators }\end{array}$} & \multirow{3}{*}{$\begin{array}{c}\text { Koszty } \\
\text { ochrony } \\
\text { [zł/ha] } \\
\text { Costs of } \\
\text { protection } \\
K_{Z} \\
{[\text { PLN/ha] }}\end{array}$} & \multirow{3}{*}{$\begin{array}{c}\text { Plon } \\
\text { handlowy } \\
\text { Market } \\
\text { yield } \\
P \\
{[\mathrm{dt} / \mathrm{ha}]}\end{array}$} & & & \multirow{3}{*}{$\begin{array}{c}\text { Nadwyżka } \\
\text { produkcji } \\
\text { uratowanej } \\
\text { [zł/ha] } \\
\text { Surplus of the } \\
\text { production } \\
N \\
{[\mathrm{PLN} / \mathrm{ha}]}\end{array}$} & \multicolumn{4}{|c|}{ Wskaźniki - Indexes } \\
\hline & & & \multicolumn{2}{|c|}{$\begin{array}{c}\text { Plon uratowany } \\
\text { Yield saved } \\
P_{u}\end{array}$} & & \multirow{2}{*}{$\begin{array}{l}\text { zwrotu } \\
\text { kosztów } \\
\text { ochrony } \\
\text { refund of } \\
\text { protection } \\
\text { costs } \\
P_{w k z} \\
{[\%]}\end{array}$} & \multirow{2}{*}{$\begin{array}{c}\text { pokrycia } \\
\text { kosztów } \\
\text { cost } \\
\text { defrayal } \\
W_{P k}\end{array}$} & \multicolumn{2}{|c|}{$\begin{array}{c}\text { orientacyjne } \\
\text { wskaźniki } \\
\text { opłacalności } \\
\text { orientation index } \\
\text { of profitability }\end{array}$} \\
\hline & & & [dt/ha] & $\begin{array}{c}{[\mathrm{zl} / \mathrm{ha}]} \\
{[\mathrm{PLN} /} \\
\mathrm{ha}]\end{array}$ & & & & $E_{1}$ & $E_{2}$ \\
\hline $1 .^{*}$ & 1202,5 & 235,7 & - & - & - & - & - & - & - \\
\hline 2. & 578,2 & 297,4 & 61,7 & 3578,6 & 3000,4 & 518,9 & 6,19 & 9,97 & 3,35 \\
\hline 3. & 1137,5 & 338,9 & 103,2 & 5985,6 & 4848,1 & 426,2 & 5,26 & 19,61 & 5,79 \\
\hline 4. & 1133,6 & 361,4 & 125,7 & 7290,6 & 6157,0 & 543,1 & 6,43 & 19,54 & 5,41 \\
\hline 5. & 1702,7 & 389,1 & 153,4 & 8897,2 & 7194,5 & 422,5 & 5,23 & 29,36 & 7,55 \\
\hline $\begin{array}{c}\text { Średnio 2-5 } \\
\text { Mean 2-5 }\end{array}$ & 1138,0 & 346,7 & 111,0 & 6438,0 & 5300,0 & 477,7 & 5,78 & 19,62 & 5,53 \\
\hline
\end{tabular}

*objaśnienia jak w Materiałach i metodach - explanations as in the Materials and methods

który jest ilorazem wartości produkcji uratowanej i kosztu zabiegów, był największy w wariantach 2. i 4., w których zastosowano środki chwastobójcze - na obiekcie 2. herbicyd Harrier 295 ZC (linuron + chlomazon), na obiekcie 4. herbicyd Sencor $70 \mathrm{WG}$ (metrybuzyna). Wskaźnik $E_{1}$ kształtował się na poziomie od 9,79 dt/ha w wariancie 2 . do $29,36 \mathrm{dt} /$ ha w wariancie 5., co oznacza, że przeznaczono od 9,79 do 29,36 dt/ha plonu bulw ziemniaka, by pokryć koszty zabiegów. Równoważnik kosztów zabiegów dla ziemniaka nie powinien przekraczać $10 \%$, wówczas zabiegi ochronne są opłacalne oraz celowe. Przeprowadzone obliczenia wykazały, że na obiektach 2-5 wskaźnik ten mieścił się w granicach od 3,35 do 7,55, co świadczy że zastosowanie zabiegów mechanicznych, herbicydów i biostymulatorów było opłacalne. Nadwyżka produkcji uratowanej (N) wahała się od 3000,4 do 7194,5 zł/ha, a wskaźnik pokrycia kosztów od 5,23 do 6,43, a więc stosowane na plantacji zabiegi ochronne były opłacalne, co potwierdzają wcześniejsze badania Zarzeckiej i wsp. (2017). 


\section{Wnioski / Conclusions}

1. Plony bulw ziemniaka odmiany Bartek (ogólny i handlowy) zebrane z obiektów pielęgnowanych mechaniczno-chemicznie oraz z dodatkiem biostymulatorów były większe niż na poletkach odchwaszczanych tylko mechanicznie.

2. Przeprowadzone badania wykazały, że stosowane na plantacji zabiegi mechaniczno-chemiczne z użyciem biostymulatorów były opłacalne. Aplikowane biostymulatory i herbicydy obniżały koszty poniesione na pielęgnację oraz polepszały wskaźniki efektywności ekonomicznej w porównaniu do pielęgnacji wyłącznie mechanicznej.
3. Najlepszy efekt ekonomiczny uzyskano po zastosowaniu intensywnej pielęgnacji mechanicznej obejmującej dwukrotne obredlanie oraz jednokrotne obredlanie z bronowaniem, oraz po łącznej aplikacji herbicydu Sencor 70 WG (metrybuzyna) i biostymulatora Asahi SL.

4. Efekty ekonomiczne uprawy ziemniaka należy stale kontrolować, ze względu na zmieniające się ceny preparatów, wprowadzanie nowych odmian oraz wielkość zbieranych plonów.

Wyniki badań zrealizowane w ramach tematu badawczego nr 214/04/S, zostały sfinansowane z dotacji na naukę, przyznanej przez Ministerstwo Nauki i Szkolnictwa Wyższego.

\section{Literatura / References}

Baranowska A., Mystkowska I., Zarzecka K. 2018. Zachwaszczenie łanu ziemniaka (Solanum tuberosum L.) w warunkach stosowania biostymulatorów i herbicydu. [The weed infestation of the potato (Solanum tuberosum L.) field under the conditions of growth biostymulators and herbicide applications]. Progress in Plant Protection 58 (4): 275-281. DOI: 10.14199/ppp-2018-038.

Golinowska M. 2009. Nakłady na chemiczną ochronę roślin w gospodarstwach wielkoobszarowych na początku XXI wieku. [Chemical plant protection outlays in vast areas farming at the beginning of 21 st century]. Journal of Agribusiness and Rural Development 2 (12): 53-60.

Gugała M., Zarzecka K. 2006. Efektywność ekonomiczna ochrony ziemniaka przed chwastami. [Economic effectiveness of potato protection against weeds]. Zeszyty Problemowe Postępów Nauk Rolniczych 511 (2): 441-449.

Gugała M., Zarzecka K., Dołęa H., Sikorska A. 2018. Weed infestation and yielding of potato under conditions of varied use herbicides and bio-stimulants. Journal of Ecological Engineering 19 (4): 191-196. DOI: 10.12911/22998993/89654.

Gugała M., Zarzecka K., Sikorska A. 2013. Ocena skuteczności działania herbicydów i ich wpływ na plon handlowy ziemniaka. [Evaluation of herbicide efficiency and their influence on potato marketable yield]. Biuletyn Instytutu Hodowli i Aklimatyzacji Roślin 270: 75-84.

Gugała M., Zarzecka K., Zadrożniak B. 2010. Wpływ adiuwantów na plonowanie i ograniczenie zachwaszczenia na plantacji ziemniaka. [An effect of adjuvants on potato yielding and limiting weed infestation in potato stands]. Biuletyn Instytutu Hodowli i Aklimatyzacji Roślin 255: 47-57.

Krzysztofik B., Marks N., Baran D. 2009. Wpływ wybranych czynników agrotechnicznych na ilościowe cechy plonu bulw ziemniaka. [The impact of selected agrotechnical factors on the quantitative characteristics of potato tuber crop]. Inżynieria Rolnicza 5 (114): $123-129$.

Kulig B., Oleksy A., Sajdak A. 2006. Plonowanie wybranych odmian bobiku w zależności od sposobu ochrony roślin i gęstości siewu. [Yielding of selected Faba bean cultivars depending on plant protection methods and sowing density]. Fragmenta Agronomica 26 (3): 93-101.

Mierzejewska W. 1989. Rachunek kosztów w ochronie roślin. [Calculation of costs in the plant protection]. Zeszyty Problemowe Postępów Nauk Rolniczych 363: 9-22.

Mierzejewska W. 1991. Ochrona roślin jako nakład gospodarczy. [Plant protection as an economic input]. Roczniki Nauk Rolniczych, Seria G, 85 (3): 67-79.

Paradiković N., Vinković T., Vinković-Vrček I., Žuntar I., Bojić M., Medić-Šarić M. 2011. Effect of natural biostimulants on yield and nutritional quality: an example of sweet yellow pepper (Capsicum annuum L.) plants. Journal of the Science of Food and Agriculture 91 (12): 2146-2152. DOI: $10.1002 /$ jsfa.4431.

Pytlarz-Kozicka M., Golinowska M. 2006. Efektywność ekonomiczna ochrony roślin w uprawie ziemniaków z różnych grup wczesności [Economic effectiveness of crop protection in the cultivation of potatoes from various groups of earliness]. Progress in Plant Protection 46 (1): 312-318.

Rozporządzenie Ministra Rolnictwa i Rozwoju Wsi z dnia 29 października 2003 r. w sprawie szczegółowych wymagań w zakresie jakości handlowej ziemniaków. [Regulation of the Minister of Agriculture and Rural Development of 29 October 2003 on detailed requirements for commercial quality of potatoes]. Dz. U. nr 194 poz. 1900 z 19 listopada 2003 r.

Skowera B. 2014. Zmiany warunków hydrotermicznych na obszarze Polski (1971-2010). [Changes of hydrothermal conditions in the Polish area (1971-2010)]. Fragmenta Agronomica 31 (2): 74-87.

Trawczyński C. 2014. Wpływ biostymulatorów aminokwasowych - tecamin - na plon i jakość ziemniaków. Ziemniak Polski 3: $29-34$.

Urbanowicz J. 2015. Herbicydy zalecane do ochrony ziemniaka. Ziemniak Polski 2: 25-29.

Wereszczaka J., Marczakiewicz J. 2014. Zrównoważone rolnictwo i zdrowe środowisko. Dobre praktyki i rola pożytecznych mikroorganizmów w uprawie ziemniaków z zastosowaniem innowacyjnych, naturalnych technologii. Ministerstwo Rolnictwa i Rozwoju Wsi, Fundacja Programów Pomocy dla Rolnictwa FAPA, 104 ss. ISBN 978-83-939158-2-8.

Zarzecka K., Gugała M., Mystkowska I., Baranowska A. 2014. Wpływ herbicydów i ich mieszanin na wielkość plonu ubocznego bulw ziemniaka. [The effect of herbicides and their mixtures on the side yield of potato tubers]. Acta Agrophysica 21 (3): 375-385.

Zarzecka K., Gugała M., Mystkowska I., Baranowska A., Głuszczak B. 2017. Ekonomiczna ocena różnych sposobów odchwaszczania ziemniaków jadalnych. [Economic evaluation of different systems of weed control of edible potatoes]. Roczniki Naukowe Stowarzyszenia Ekonomistów Rolnictwa i Agrobiznesu 19 (3): 308-311. DOI: 10.5604/01.3001.0010.3268. 